\title{
Multiple aspects of gene dysregulation in Huntington's disease
}

\section{Lara Moumné, Sandrine Betuing and Jocelyne Caboche*}

Laboratoire de Physiopathologie des Maladies du Système Nerveux Central, Neuronal Signaling and Gene Regulation, CNRS-UMR7224, INSERM-UMS952, Université Pierre et Marie Curie-Paris 6, Paris, France

\section{Edited by:}

Thomas M. Durcan, McGill University, Canada

Reviewed by:

A. Jennifer Morton, University of Cambridge, UK

Thomas M. Durcan, McGill University, Canada

Wenjun Song, Washington University in Saint Louis School of Medicine, USA

\section{*Correspondence:}

Jocelyne Caboche, Laboratoire de Physiopathologie des Maladies du Système Nerveux Central, Neuronal Signaling and Gene Regulation, CNRS-UMR7224, INSERM-UMS952, Université Pierre et Marie Curie-Paris 6, 9 quai Saint Bernard, 75005 Paris,

France

e-mail: jocelyne.caboche@

snv.jussieu.fr
Huntington's Disease (HD) is a genetic neurodegenerative disease caused by a CAG expansion in the gene encoding Huntingtin $(H t t)$. It is characterized by chorea, cognitive, and psychiatric disorders. The most affected brain region is the striatum, and the clinical symptoms are directly correlated to the rate of striatal degeneration. The wild-type $\mathrm{Htt}$ is a ubiquitous protein and its deletion is lethal. Mutated (expanded) Htt produces excitotoxicity, mitochondrial dysfunctions, axonal transport deficit, altered proteasome activity, and gene dysregulation. Transcriptional dysregulation occurs at early neuropathological stages in HD patients. Multiple genes are dysregulated, with overlaps of altered transcripts between mouse models of HD and patient brains. Nuclear localization of Exp-Htt interferes with transcription factors, co-activators, and proteins of the transcriptional machinery. Another key mechanism described so far, is an alteration of cytoplasmic retention of the transcriptional repressor REST, which is normally associated with wild-type $\mathrm{Htt}$. As such, Exp-Htt causes alteration of transcription of multiple genes involved in neuronal survival, plasticity, signaling, and mitochondrial biogenesis and respiration. Besides these transcriptional dysregulations, Exp-Htt affects the chromatin structure through altered post-translational modifications (PTM) of histones and methylation of DNA. Multiple alterations of histone PTM are described, including acetylation, methylation, ubiquitylation, polyamination, and phosphorylation. Exp-Htt also affects the expression and regulation of non-coding microRNAs (miRNAs). First multiple neural miRNAs are controlled by REST, and dysregulated in $\mathrm{HD}$, with concomitant de-repression of downstream mRNA targets. Second, Exp-Htt protein or RNA may also play a major role in the processing of miRNAs and hence pathogenesis. These pleiotropic effects of Exp-Htt on gene expression may represent seminal deleterious effects in the pathogenesis of HD.

Keywords: transcription, epigenetics, chromatin remodeling, histone modifications, REST, miRNAs

\section{INTRODUCTION}

Huntington's disease (HD) is a dominantly inherited genetic disorder induced by an abnormal expansion of a CAG trinucleotide repeat at the $5^{\prime}$ terminal part of the Huntingtin (Htt) gene leading to a polyglutamine expansion in the Htt protein (1). It is the most frequent genetic disease induced by a polyglutamine expansion with a prevalence of three to seven for 100,000 persons. Individuals with 39 CAG repeats or more will develop the clinical symptoms and signs of HD including neuropsychiatric, motor, and cognitive abnormalities that cause a progressive loss of functional capacity and shorten life span $(2,3)$. Intermediate alleles repetitions (between 36 and 39 repeats) are usually associated with late onset disease and may express a variable penetrance as the patient may die before disease onset (4-6). HD has a well-defined neuropathology, and informative pre-manifest predictive genetic testing. Brain weight may be reduced by as much as $25-30 \%$ in advanced HD cases. Gross pathology in HD is mainly observed in the brain, with atrophy predominating in the caudate-putamen, and to a lesser extent, the cerebral cortex. Furthermore, despite the early expression of mutated $\mathrm{Htt}(\mathrm{Exp}-\mathrm{Htt})$ in all neuronal cells the first symptoms and neuropathological hallmarks appear at adulthood, around $40-45$ years old. The age of onset of the disease is conversely proportional to the number of CAG repeats in the affected allele. Once the first symptoms have appeared, the disease progresses and leads progressively to death. As neuro-degeneration progresses in the striatum, the severity of symptoms increases (2). Magnetic resonance imaging (MRI) studies indicate that striatal atrophy begins up to 15 years before predicted onset and continues through the period of manifest illness (7). Therefore, the pre-symptomatic phase in HD provides a unique window for therapeutic intervention and neuro-protection.

The clinical features of HD can be divided into three groups: movement disorders, cognitive impairment, and psychiatric manifestations [see Ref. (8) for review]. Chorea is the most characteristic movement disorder of HD and is characterized by brief, involuntary, abnormal movements, which appear unpredictably in all the parts of the body. Cognitive impairment can precede motor symptoms or occur during the course of the disease, and usually leads, in turn, to dementia. Neurobehavioral symptoms include irritability, agitation, apathy, anxiety, social 
withdrawal, impulsiveness, alcohol abuse, obsessive-compulsive disorder. Mood disorders are very frequent, including depression and HD patients have a risk of suicide that is 10 times higher than in the general population.

There is no cure for HD, although medication can be given to help control the emotional and movement problems associated with HD. While medicines may help keep clinical symptoms under control, they are unable to stop or reverse the course of the disease.

Basic research has provided new insights into the complex cellular and molecular alterations involved in the pathogenesis of HD. The wild-type Htt is an ubiquitous protein, expressed in most cells and within all cellular compartments (9). It is required for normal embryonic development, and $H t t$ knock-out mice show early lethality $(\mathrm{E} 8,5)(10,11)$. Furthermore, selective knock-down of the Htt protein in neurons and testis produces apoptosis in these tissues (12). Whether neuronal degeneration in HD is due to loss of normal function of wild-type Htt, or gain of toxic functions of Exp-Htt is still a debate. Expansion of polyglutamine in Htt leads to protein aggregation (9), a mechanism thought to be primarily involved in several neurological disorders caused by CAG repeats. It still remains to be established whether the mutant Htt aggregates are incidental, pathogenic, or neuroprotective. Expansion of polyglutamine in $\mathrm{Htt}$ produces by itself multiple cellular dysfunctions, including excitotoxicity, altered mitochondrial functions, axonal transport deficit, altered proteasome activity, and gene dysregulation, that were extensively described in other reviews $(8,13)$. Among these alterations, transcriptional dysregulation occurs at early neuropathological stages in HD and seems to be seminal in the neuropathological process.

\section{TRANSCRIPTIONAL DYSREGULATION IN HD}

Dysregulation of transcription was first described in HD brain tissues at early neuropathological stages and then found in presymptomatic HD transgenic mice. Expression of enkephalin, substance $\mathrm{P}$, dopamine D1 and D2 receptor mRNAs were shown to be altered in the caudate-putamen of HD patients in post mortem tissue in the early grade using in situ hybridization (14). Subsequently, cDNA microarray performed on genetically engineered HD mouse models allowed thousands of genes to be monitored, and provided a global genomic view of striatal dysfunctions in HD. From these analysis, neurotransmitter receptors, enzymes, and proteins involved in neuron structure, stress response, and axonal transport were found to be dysregulated (15-20). These changes were reproducibly observed in various HD mouse models and in the human HD caudate-putamen (19). Altogether these observations strongly supported that changes in transcription underlie neuro-degeneration rather than unspecific degradation of all RNAs in affected neurons.

Importantly, more than $81 \%$ of striatal-enriched genes (genes with higher relative expression in the striatum when compared to other brain regions) are decreased in a HD mouse model and in the caudate of HD patients (21). Down-regulation of novel striatal-enriched genes involved in vesicle transport and trafficking, tryptophan metabolism and neuroinflammation have also been identified in both HD mouse striatum and caudate from HD patients (22). Transcriptional dysregulation occurs in large genomic regions, in a coordinated fashion and is associated with disease progression. Hence genome-wide expression profiling of the blood from HD patients revealed significant differences in symptomatic patients (23) but not moderate-stage patients (20). Thus, these biomarkers need to be further validated before their widespread use in clinical trials.

\section{PATHOGENIC INTERACTION OF EXP-HTT WITH NUCLEAR PROTEINS}

Huntingtin has multiple interacting partners, among which are transcription factors or co-activators of the transcriptional machinery, some of them exhibiting enhanced binding with Exp$\mathrm{Htt}$, while a handful prefers binding with wild-type $\mathrm{Htt}(24,25)$. Due to its polyglutamine expansion, Exp-Htt abnormally interacts with several proteins involved in transcription regulation. These include the global transcriptional regulator TATA-binding protein/TFIID (26), TAFII130, a co-activator involved in cAMPresponsive element binding protein (CREB)-dependent transcription (27). An abnormal interaction of Exp-Htt has also been shown with specificity protein 1 (Sp1) (28), p53, CREB binding protein (CBP) $(29,30)$, and nuclear receptor co-repressor (NCoR) (31). The global consequence of these pathogenic interactions is a widespread transcriptional dysregulation. Thus, overexpression of Sp1 and TAFII130 in cultured striatal cells reverses the transcriptional inhibition of the dopamine D2 receptor gene caused by Exp-Htt, and protects neurons from Exp-Htt-induced cellular toxicity (28). Exp-Htt induces upregulation of p53 and its downstream targets, Bax and Puma, both in vitro and in postmortem brains of HD patients $(32,33)$. This results in mitochondrial membrane depolarization and decreased complex IV activity. p53 inhibition or its genetic deletion ameliorates mitochondrial defects in HD cell cultures (33).

CRE-regulated genes have been well described for their role in neuronal survival (34) and impairment of CRE-dependent transcription can account for the neurodegenerative process in HD. One of the CRE-regulated genes that has been directly associated with striatal neuro-degeneration is the peroxisome proliferatoractivated receptor co-activator- $1 \alpha$ (PGC- $1 \alpha)$, a transcriptional co-activator that controls the expression of genes involved in mitochondrial biogenesis, respiration and glucose/fatty acid metabolism (35). Exp-Htt is known to cause energy dysfunction that is mainly related to mitochondrial abnormalities (36-38). Expression of PGC1- $\alpha$ is down-regulated in HD patients and HD mice (39). This down-regulation is explained by an interference of Exp-Htt with the CREB/TAF4-dependent transcriptional pathway. Cross-breeding of $P g c-1 \alpha$ knock-out mice with HD knockin mice leads to increased degeneration of striatal neurons and motor abnormalities in the HD mice, whereas lentiviral-mediated overexpression induces neuro-protection. Decreased expression of PGC1- $\alpha$ accounts for abnormal myelination in HD, since ExpHtt-induced down-regulation of PGC1- $\alpha$ in oligodendrocytes leads to inhibition of genes involved in myelination (40). PGC1$\alpha$ can also control extrasynaptic NMDAR activity in neurons, which contributes to excitotoxicity in HD (41). Suppression of PGC1- $\alpha$ contributes to Exp-Htt-induced increase in extrasynaptic NMDAR activity and vulnerability. Others key regulators of PGC$1 \alpha$, are Mitogen and Stressed-activated protein Kinase-1 (MSK1), and SIRT3. MSK-1 is a striatum-enriched nuclear protein 
kinase, targeted by the pro-survival Extracellular-signal Regulated Kinase (ERK) signaling pathway. By regulating CREB phosphorylation, along with histone $\mathrm{H} 3$ phosphorylation, MSK-1 is directly involved in the expression levels of PGC-1 $\alpha$, and as such protects against Exp-Htt-induced striatal death in vitro and in vivo (42, 43) (see below). SIRT3 is one the seven mammalian homologs of the sirtuin gene family. This mitochondrial deacetylase, initially described in brown adipocytes, regulates mitochondrial functions and thermogenesis (44). In response to exercise, SIRT3 controls CREB phosphorylation and PGC- $1 \alpha$ expression, via AMPactivated protein kinase (AMPK) (45). Exp-Htt induces decreased deacetylase activity of SIRT3 and further leads to reduction in cellular $\mathrm{NAD}(+)$ levels and mitochondrial biogenesis in cells. Viniferin, a natural compound that activates AMPK and enhances mitochondrial biogenesis, is neuroprotective in HD cellular models, an effect that tightly depends on SIRT3 activity (46). Strikingly, the sirtuin family members seem to be intimately linked to pathogenesis in $\mathrm{HD}$, since the NAD+-dependent deacetylase activity of SIRT1 is also involved in the regulation of transcription in HD. SIRT1 is a nuclear protein that normally controls CREB phosphorylation levels via TORC1 (Regulated transcription co-activator 1 (TORC1) activity $(47,48)$. By interacting with SIRT1, ExpHtt inhibits its deacetylase activity, and causes hyperacetylation of TORC1. This results in a decrease of CREB-regulated genes, including BDNF, and probably PGC1- $\alpha$.

Altogether, these data strongly support that transcriptional dysregulation in $\mathrm{HD}$ plays a major role in mitochondrial dysfunctions and energy metabolism deficit, two important hallmarks of the pathology.

\section{IMPAIRMENT OF CYTOSOLIC SEOUESTRATION OF REST}

Wild-type Htt sequesters R element-1 silencing transcription factor (REST), a transcriptional repressor of neuronal survival factors, including brain-derived neurotrophic factor (BDNF). This neurotrophic factor is expressed by cortical neurons, which project to the striatum, and is critical for striatal survival. Interestingly, both transcriptional regulation and axonal transport of BDNF $(49,50)$ are altered in HD. Htt interacts with REST in the cytoplasm, and this interaction is impaired by Exp-Htt. Thus, increased nuclear translocation of REST is observed in the presence of Exp-Htt. Locally, REST exerts a potent inhibitory role on $B d n f$ transcription and other neuronal genes $(49,51,52)$. In this context, the consequence of the loss of function of Htt is directly correlated with HD pathogenesis. Expression level of BDNF is decreased in the striatum of HD patients and in the cortex of HD mouse models $(49,53,54)$. Down-regulation of BDNF in the striatum specifically worsens the HD phenotype, whereas elevating BDNF expression in the forebrain alleviates it (54-58). The role of REST in HD may not be restricted to the regulation of $B d n f$ transcription since several REST targets are known to be dysregulated in $\operatorname{HD}(52,58)$. REST seems to have a widespread role on gene dysregulation in $\mathrm{HD}$, since it also controls non-coding RNAs (see below). In vivo delivery of a dominant negative form of REST in the motor cortex restores the expression of BDNF mRNA and protein along with other REST-regulated genes in this region (59). Surprisingly, despite this important effect on gene regulation, no therapeutic effects were found in motor function in HD mouse models. These data raised the question as to whether a more widespread rescue of REST-regulated genes in the brain may be necessary.

\section{CHROMATIN REMODELING IN HUNTINGTON'S DISEASE}

Chromatin remodeling is an "above the genome" molecular mechanism, that gates DNA access, and hence transcription. It is critically controlled by post-translational modifications (PTM) of histones ( $\mathrm{H} 2 \mathrm{~A}$ and $\mathrm{H} 2 \mathrm{~B}, \mathrm{H} 3$ and $\mathrm{H} 4$ ), a group of highly basic proteins tightly linked to DNA. By modifying the electrostatic interactions between the N-terminal domain of histones and DNA, PTM of histones contribute to the chromatin structure, and access of the transcriptional machinery to the DNA (60). In particular, the methylation or acetylation state of histones is closely linked to regions of transcriptional activity, by regulating transcription factor access to promoter regions in the DNA.

The enzymes that catalyze histone acetylation are histone acetyltransferases (HATs) whereas Histone Deacetylases (HDACs), catalyze the reverse deacetylation reaction (60-62). By interacting with CBP and p300/CBP-associated factor (P/CAF), Exp-Htt blocks their intrinsic HAT activity $(29,30,63,64)$. This results in a global reduction of histones $\mathrm{H} 3$ and $\mathrm{H} 4$ acetylation levels, along with CBP-regulated gene transcription. Overexpression of CBP reduces Exp-Htt-induced toxicity (30).

Determining experiments were performed to demonstrate that HDAC inhibitors (HDACis), including SAHA, sodium butyrate, or phenylbutyrate improved behavioral performance and increased neuronal survival in several HD models (64-67). These data lead to the general concept that HDACi could be a new therapeutic avenue in HD. This concept is however weakened by the toxicity of the aforementioned HDACi compounds at therapeutic doses. Furthermore, it must be emphasized that the levels of acetylated histones are not decreased globally in HD mouse models, but rather selectively in the promoters of genes that are specifically down-regulated in HD (68).

So far, HDACis act broadly on the HDAC family, which comprises 11 members divided into four classes: I (HDAC1, 2, 3 and 8), IIa (HDAC4, 5, 7 and 9), IIb (HDAC6 and 10), and IV (HDAC11) (69). Their relative toxicity can be due to either inhibition of a pro-survival HDAC isoform, or low substrate specificity, a single enzyme being capable of deacetylating multiple sites within histones (60). Thus, it was postulated that inhibitors targeting one specific HDAC might produce a better benefit to side effect ratio.

To unravel this issue, genetic invalidation of each single HDAC was investigated in the R6/2 mouse model. These studies revealed that reduction of $\mathrm{Hdac} 3,5,6,7$, and 9 expression had no effect on HD-related phenotype (70-72), whereas reduction of Hdac4 expression showed a significant beneficial effect (73). This raises the interesting question as to whether specific HDAC4 inhibitors may be more adapted for HD treatment, an issue that is now under investigation (73).

Methylation of histones affects lysine and arginine residues and is associated to either activation or repression of transcription, depending on the modified residues. One of the proteins involved in methyltransferase activity at histone H3 (K9) is ERG-associated protein with SET domain (ESET). ESET expression is increased in $\mathrm{HD}$ patients and R6/2 HD mice (74). Sp1 acts as a transcriptional activator of the ESET promoter at guanosine-cytosine 
(GC)-rich DNA binding sites (75). Inhibiting Spl binding to these sites using mitramycin (a clinically approved antitumor antibiotic) suppressed basal ESET promoter activity in a dose dependent manner and lead to extended survival, enhanced motor performance and improved brain histopathology in R6/2 mice (74). Interestingly, the reduction of $\mathrm{H} 3 \mathrm{~K} 9$ hypermethylation induced by mithramycin or chromomycin, is associated with an increased acetylation of the same residue (76). On the other hand, the beneficial effect of the HDACi phenylbutyrate in HD mice is accompanied by an increase in $\mathrm{H} 3$ and $\mathrm{H} 4$ acetylation and a concomitant decrease in H3 methylation (67). These data illustrate that a crosstalk between acetylation and methylation participates to the nucleosomal dynamics, and that disequilibrium between these two epigenetic marks can be corrected by the inhibition of either deacetylation or methylation.

Monoubiquitylation of histones has also been implicated in HD-related transcriptional dysregulation. This modification, which involves E3-ubiquitin ligase complexes, affects lysine residues of histone $\mathrm{H} 2 \mathrm{~A}(\mathrm{uH} 2 \mathrm{~A})$ and $\mathrm{H} 2 \mathrm{~B}(\mathrm{uH} 2 \mathrm{~B})$ and is associated to either activation or repression of transcription depending on the modified residues. Exp-Htt expression alters the activity of specific E3-ubiquitin ligases, and modifies $\mathrm{uH} 2 \mathrm{~A}$ and $\mathrm{uH} 2 \mathrm{~B}$. Knocking down the $\mathrm{H} 2 \mathrm{~A} \mathrm{E} 3$-ubiquitin ligase reduces $\mathrm{uH} 2 \mathrm{~A}$ and rescues transcriptional repression in Exp-Htt knock-in cells. In contrast, knocking down the H2B E3-ubiquitin ligase induces transcriptional repression in wild-type Htt knock-in cells (77).

Core histones can be post-translationally modified by transglutaminases (TG), which catalyze transamidation of glutamine residues. All four mammalian core histones, $\mathrm{H} 2 \mathrm{~A}, \mathrm{H} 2 \mathrm{~B}, \mathrm{H} 3$, and $\mathrm{H} 4$, were shown to be glutaminyl substrates of TG2, a nuclear $\mathrm{TG}$, and their crosslinking contributes to chromatin condensation in vitro (78-80). Total TGs activity is elevated in brain extracts from HD patients (81) and treatment of R6/2 mice with a TG competitive inhibitor, cystamine, extends survival, reduces tremor and abnormal movements and ameliorates weight loss in these mice (82). Therefore, TGs were suggested to participate to chromatin remodeling and gene expression dysregulation in HD. McConoughey and colleagues showed that TG2 polyaminates H3 $\mathrm{N}$-terminal tail which increases its positive charge and therefore its propensity to more tightly interacts with DNA (83). TG2 occupies the promoter/enhancer regions of two genes essential for energy production, PGC1- $\alpha$ and cytochrome $c$, and a selective inhibition of TG2 in a HD striatal cell line corrects gene dysregulation. Therefore TG2 inhibition has emerged as a HDAC-independent epigenetic therapeutic strategy for HD.

Histone phosphorylation is mainly described as an activating chromatin mark of gene activation. This PTM affects serine, threonine and tyrosine residues. Histone phosphorylation is controlled by the interplay between kinases and phosphatases that respectively add and remove phosphate onto each of these residues. Histone kinases phosphorylate the hydroxyl group of the targeted amino-acid side chain therefore leading to a change of the global charge of histones, a reduced interaction between histones and DNA and a relaxation of chromatin (60). Phosphorylation of H3S10 involves MSK-1 that was shown to be down-regulated in HD cells, mice and patients (42). Restoration of MSK-1 expression in striatal neurons in vitro and in the lentiviral-based rat model of HD protects against neuronal dysfunctions induced by Exp-HTT $(42,43)$. In contrast, MSK-1 knock-out mice exhibit spontaneous striatal atrophy when they age, and a higher sensitivity to the 3-nitropropionic acid (3NP), a mitochondrial neurotoxin that induces selective degeneration of striatal neurons and HD-like symptoms in humans, monkeys, and rodents (43). In addition to its H3S10-kinase activity, MSK-1 phosphorylates, and activates CREB, leading to the regulation of PGC- $1 \alpha$, both in vitro and in vivo (Figure 1).

In addition to histone PTMs, chromatin remodeling is controlled by DNA methylation. A recent study showed that Exp-HTT induces an extensive alteration of DNA methylation on a large proportion of genes that change in expression in HD (84). The authors of this study identified more specifically two transcriptional regulators, AP-1 and Sox2, associated with DNA methylation changes. Since these epigenetic changes are more stable, this could explain the long-term modifications of gene expression in HD.

\section{HD AND miRNAs}

About $98 \%$ of human transcribed genome is dedicated to nonprotein-coding RNAs (NcRNAs) genes, with regulatory properties on gene expression. Among ncRNAs, microRNAs (miRNAs) are 21-23 nucleotide RNA molecules that regulate gene expression by promoting either degradation or translational-inhibition of target mRNAs (85). The miRNA pathway starts in the nucleus with the RNA polymerase II-mediated transcription of primary (pri-miRNAs) hairpins, which are cleaved into precursor of miRNAs (pre-miRNAs) by the nuclear proteins Drosha and DiGeorge syndrome critical region 8 (DGRC8) $(86,87)$. Pri-miRNAs are then transported to the cytoplasm $(88,89)$ and processed into 22nt duplex mature miRNAs by the RNAseIII Dicer (90), which is then assembled into the RNA-induced silencing complex (RISC) with the protein Argonaute (Ago) (91). MiRNAs suppress post-transcriptional expression of genes by guiding RISC interaction with their specific sequence motifs within the $3^{\prime}$ untranslated region ( $\left.3^{\prime} \mathrm{UTR}\right)$. This results in either degradation or translational-inhibition of the target mRNAs (92-95).

Many miRNAs are selectively and abundantly expressed in the CNS where they play key roles in the elaboration of the neuronal transcriptome (96) and seem to be important mediators of plasticity (97). MiRNA dysregulation has been associated with several human disorders of the CNS. The first evidence came from studies showing that Dicer or DGCR8 ablation impairs neuronal differentiation, produces synaptic dysfunctions, disturbs axonal path-findings, and induces neuro-degeneration, suggesting that miRNAs play important roles in neurological disorders $(98,99)$. Evidence of miRNA dysregulation in HD exists. Two different and complementary aspects of this dysregulation arise from the recent literature. First, there is now increasing evidence that multiple neural miRNAs are decreased in HD neurons, with concomitant de-repression of downstream target mRNAs (58, 100-102). Second, several elegant studies demonstrate that Exp-HTT protein (103) or RNA (104) may play a major role in the processing of miRNAs and hence pathogenesis.

Using an in silico approach, the group of Cataneo identified 17 miRNA genes as likely targets of REST (58) (Figure 2). The regulation of these miRNAs by REST was evaluated in embryonic 


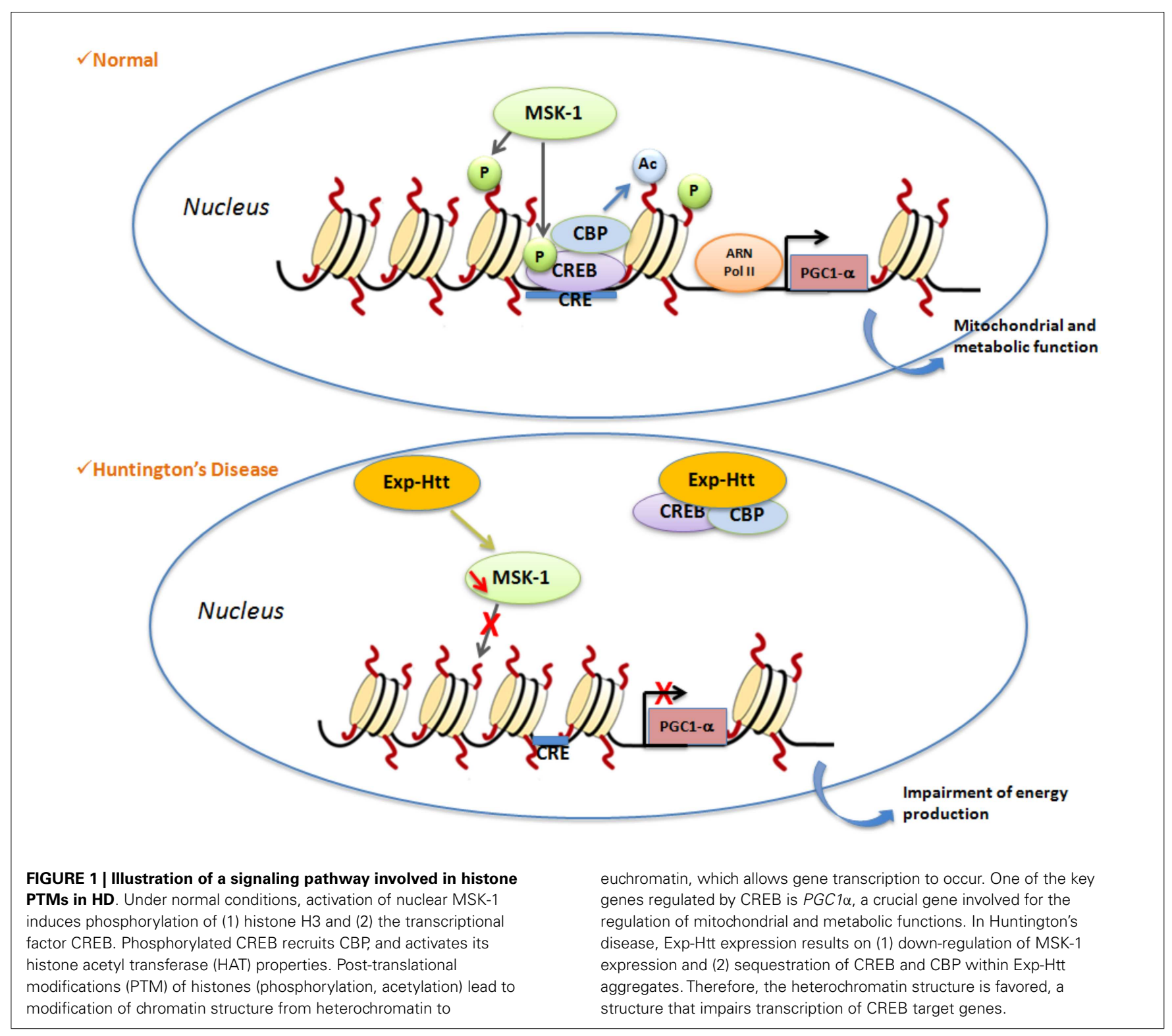

striatal cell lines, and mir-29a, mir-124a, mir-132, and mir-135b were shown to be significantly upregulated upon loss of REST function and in the cortex of 12-week-old R6/2 mice. In humans, mir-132 expression level is significantly lower in HD samples compared to control. In contrast, mir-29a and mir-330 expression is significantly higher in HD samples. Packer et al. (102) used a screen of predicted REST-regulated miRNAs from HD patient brain samples, and found significant decreases of miR-9, miR$9^{*}$, and miR-29b as well as a significant increase of miR-132 at late stages. They also found that the bi-functional brain enriched miR-9/miR-9* targets two components of the REST complex: miR9 targets REST and miR- $9^{\star}$ targets CoREST. A characterization of miRNAs profiling and sequence modification was performed by Illumina sequencing in the frontal cortex and the striatum. It showed a strong deregulation of miRNA and IsomiRs (miRNAs containing length and sequence heterogeneity) in HD, most being common to both frontal cortex and striatum (105). Of interest, the co-regulated miRNAs contained regulatory sequences for REST and p53, suggesting a key role of these genes in down-regulation of gene expression in HD. Profiling of miRNAs expression was also performed in the YAC128 and R6/2 mice, showing that nine miRNAs (miR-22, miR-29c, miR-128, miR-132, miR-138, miR-218, miR-222, miR-344, and miR-674*) are commonly down-regulated in 12-month-old YAC128 mice and 10-week-old R6/2 mice (100). Concomitantly, the expression of Dicer is decreased at the late stages in these two mouse lines, indicating that miRNA biogenesis is altered in HD. More recently, Soldati and collegues, found the same results in HD cell lines (101). Rescuing miR-22 expression in in vitro HD models, protected against Exp-Htt-induced neurotoxicity (106). Very recently, miR-196a was shown to reduce the expression of Exp-HTT in vitro, and to improve molecular, pathological, and behavioral phenotypes in a HD transgenic 

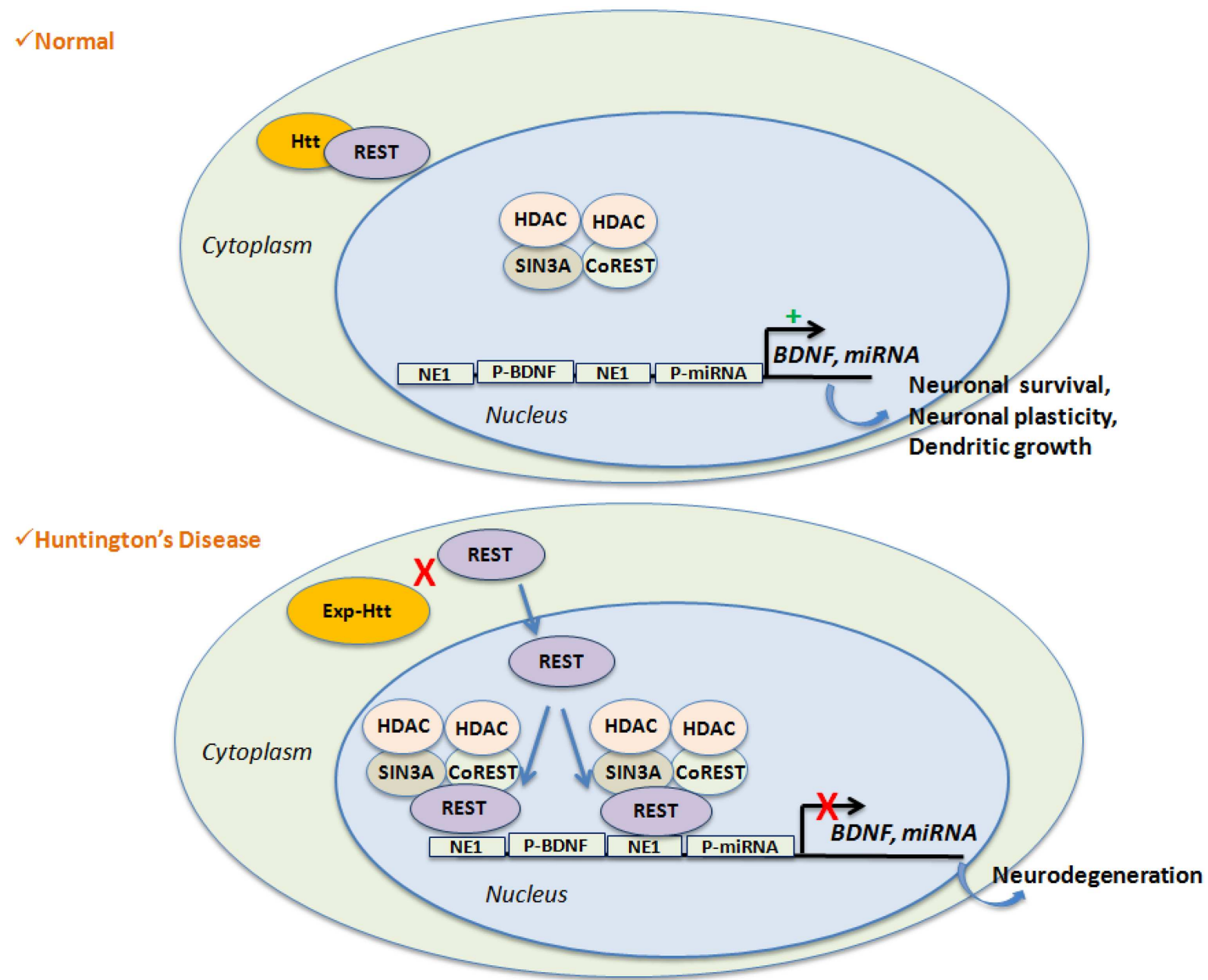

FIGURE 2 | REST-mediated gene repression is favored in HD. Wild-Type $\mathrm{Htt}$ interacts with REST, a transcriptional repressor, within the cytoplasm. This leads to de-repression of REST target genes like BDNF or non-coding miRNAs, which are essential for neuronal survival, neuronal plasticity or dendrites growth. Expansion of Htt disrupts its binding with REST and facilitates nuclear entry of REST along with the formation of the repressor complex on the RE1 site. Activation of RE1 site results on target gene silencing and participates to neuro-degeneration. mouse model (107). Of importance, miR-196a ameliorated the formation of aggregates in iPSC (inducible Pluripotent Stem Cells) from HD patients, when differentiated in the neuronal stage. The down-regulation of Exp-HTT by miR-196a is of prime importance, since it forms the bases of new strategies for allele-specific silencing in HD. miR-196a did not regulate Exp-Htt levels directly, but rather indirectly, probably through the regulation of the ubiquitin-proteasome system, gliosis, and the CREB pathway.

Additionally, HTT has a more direct role in post-transcriptional gene silencing by miRNAs. An elegant study from Naoko Tanese's group (103) has shown that HTT itself contributes to RNAmediated gene silencing through its association with Ago in Processing bodies (P-bodies). Mouse striatal cells expressing ExpHtt showed fewer P-bodies and reduced reporter gene silencing activity compared to wild-type. More recently, a pathogenic role of the Exp-HTT RNA was provided (104). The authors showed that Exp-HTT mRNA generates small CAG-repeated RNAs (sCAGs) having a neurotoxic activity. This toxic effect was dependent on Dicer and Ago proteins, as they were inhibited by their knock-down. They thus provide the first demonstration that these sCAGs generated by Exp-HTT may contribute significantly to the neuro-degeneration pattern observed in HD.

\section{CONCLUSION}

Most of the cellular dysfunctions in HD are due to alterations of gene expression: from mitochondrial dysfunctions and metabolism energy deficit, to excitotoxicity. Furthermore, dysregulation of transcription is a widespread, reproducible, and early event in the pathogenic process of HD. Therefore, new therapeutic approaches targeting transcription factors, chromatin remodeling, or miRNAs can be proposed. Obviously targeting signaling pathways that control expression levels of the trophic factor BDNF or the mitochondrial gene PGC1- $\alpha$ will provide interesting perspective. Targeting the REST transcriptional repressor, CREB, or Sirtuins remain interesting strategies. Although therapeutic trials, including safety 
and tolerability studies, with the global HDACi, phenylbutyrate, have been conducted in patients, these compounds remain highly unspecific, since they act on multiple classes of HDACs, hence on numerous non-selected genes and sometimes non-nuclear targets. Alternative approaches could be to design compounds that target more specifically one type of HDAC, for example HDAC4 an issue that is under investigation - or to target other PTMs of histones (including phosphorylation, methylation, ubiquitylation, or polyamination), each PTM targeted alone, or in combination.

\section{REFERENCES}

1. The Huntington's Disease Collaborative Research Group. A novel gene containing a trinucleotide repeat that is expanded and unstable on Huntington's disease chromosomes. Cell (1993) 72:971-83. doi:10.1016/00928674(93)90585-E

2. Aylward EH, Codori AM, Rosenblatt A, Sherr M, Brandt J, Stine OC, et al. Rate of caudate atrophy in presymptomatic and symptomatic stages of Huntington's disease. Mov Disord (2000) 15:552-60. doi:10.1002/15318257(200005)15:3<552::AIDMDS1020>3.0.CO;2-P

3. Vonsattel JP, Myers RH, Stevens TJ, Ferrante RJ, Bird ED, Richardson EP Jr. Neuropathological classification of Huntington's disease. J Neuropathol Exp Neurol (1985) 44:559-77. doi:10.1097/ 00005072-198511000-00003

4. Kenney C, Powell S, Jankovic J. Autopsy-proven Huntington's disease with 29 trinucleotide repeats. Mov Disord (2007) 22:127-30. doi: $10.1002 / \mathrm{mds} .21195$

5. Reynolds N. Re: autopsy-proven Huntington's disease with 29 trinucleotide repeats. Mov Disord (2008) 23:1795-6. doi:10.1002/ mds.21821 author reply 1793 .

6. Semaka A, Warby S, Leavitt BR, Hayden MR. Re: autopsy-proven Huntington's disease with 29 trinucleotide repeats. Mov Disord (2008) 23:1794-5. doi:10.1002/ mds.21820 author reply 1793 .

7. Aylward EH, Sparks BF, Field KM, Yallapragada V, Shpritz BD, Rosenblatt $\mathrm{A}$, et al. Onset and rate of striatal atrophy in preclinical Huntington disease. Neurology (2004) 63:66-72. doi:10.1212/01. WNL.0000132965.14653.D1

8. Roze E, Cahill E, Martin E, Bonnet $\mathrm{C}$, Vanhoutte $\mathrm{P}$, Betuing S, et al. Huntington's disease and striatal signaling. Front Neuroanat (2011) 5:55. doi:10.3389/fnana. 2011.00055

9. DiFiglia M, Sapp E, Chase KO, Davies SW, Bates GP, Vonsattel
JP, et al. Aggregation of Huntingtin in neuronal intranuclear inclusions and dystrophic neurites in brain. Science (1997) 277:1990-3. doi:10.1126/science. 277.5334.1990

10. Duyao MP, Auerbach AB, Ryan A, Persichetti F, Barnes GT, McNeil $\mathrm{SM}$, et al. Inactivation of the mouse Huntington's disease gene homolog Hdh. Science (1995) 269:407-10. doi:10.1126/science. 7618107

11. Zeitlin S, Liu JP, Chapman DL, Papaioannou VE, Efstratiadis A. Increased apoptosis and early embryonic lethality in mice nullizygous for the Huntington's disease gene homologue. Nat Genet (1995) 11:155-63. doi:10.1038/ ng1095-155

12. Dragatsis I, Dietrich P, Zeitlin S. Expression of the Huntingtinassociated protein 1 gene in the developing and adult mouse. $\mathrm{Neu}$ rosci Lett (2000) 282:37-40. doi: 10 . 1016/S0304-3940(00)00872-7

13. Roze E, Saudou F, Caboche J. Pathophysiology of Huntington's disease: from Huntingtin functions to potential treatments. Curr Opin Neurol (2008) 21:497-503. doi:10.1097/WCO. 0b013e328304b692

14. Augood SJ, Faull RL, Love DR, Emson PC. Reduction in enkephalin and substance $P$ messenger RNA in the striatum of early grade Huntington's disease: a detailed cellular in situ hybridization study. Neuroscience (1996) 72:1023-36. doi:10.1016/03064522(95)00595-1

15. Cha JH, Kosinski CM, Kerner JA, Alsdorf SA, Mangiarini L, Davies SW, et al. Altered brain neurotransmitter receptors in transgenic mice expressing a portion of an abnormal human Huntington disease gene. Proc Natl Acad Sci U S A (1998) 95:6480-5. doi:10.1073/ pnas.95.11.6480

16. Luthi-Carter R, Strand A, Peters NL, Solano SM, Hollingsworth ZR, Menon AS, et al. Decreased expression of striatal signaling

It was recently discovered that non-coding RNAs are dysregulated in HD. Because one miRNA can target multiple pathways, this suggests that miRNAs could have pleiotropic, widespread effects on HD pathogenesis. An elegant demonstration of this assumption was recently made both in vitro and in vivo, using miR-196a, including in IPSC from HD patients. One important finding in this regard was that Exp-HTT itself was down-regulated by miR196a. Therefore, a new and fascinating therapeutic avenue is now offered with miRNAs in HD.

genes in a mouse model of Huntington's disease. Hum $\mathrm{Mol}$ Genet (2000) 9:1259-71. doi:10. 1093/hmg/9.9.1259

17. Luthi-Carter R, Strand AD, Hanson SA, Kooperberg C, Schilling G, La Spada AR, et al. Polyglutamine and transcription: gene expression changes shared by DRPLA and Huntington's disease mouse models reveal contextindependent effects. Hum Mol Genet (2002) 11:1927-37. doi:10. 1093/hmg/11.17.1927

18. Sugars KL, Rubinsztein DC. Transcriptional abnormalities in Huntington disease. Trends Genet (2003) 19:233-8. doi:10.1016/ S0168-9525(03)00074-X

19. Kuhn A, Goldstein DR, Hodges A, Strand AD, Sengstag T, Kooperberg C, et al. Mutant Huntingtin's effects on striatal gene expression in mice recapitulate changes observed in human Huntington's disease brain and do not differ with mutant Huntingtin length or wild-type Huntingtin dosage. Hum Mol Genet (2007) 16:1845-61. doi:10.1093/hmg/ ddm 133

20. Runne H, Kuhn A, Wild EJ, Pratyaksha W, Kristiansen M, Isaacs JD, et al. Analysis of potential transcriptomic biomarkers for Huntington's disease in peripheral blood. Proc Natl Acad Sci U S A (2007) 104:14424-9. doi:10.1073/ pnas.0703652104

21. Desplats PA, Kass KE, Gilmartin T, Stanwood GD, Woodward EL, Head SR, et al. Selective deficits in the expression of striatal-enriched mRNAs in Huntington's disease. J Neurochem (2006) 96:743-57. doi:10.1111/j.1471-4159.2005. 03588.x

22. Mazarei G, Neal SJ, Becanovic K, Luthi-Carter R, Simpson EM, Leavitt BR. Expression analysis of novel striatal-enriched genes in Huntington disease. Hum Mol Genet (2010) 19:609-22. doi:10. 1093/hmg/ddp527

23. Borovecki F, Lovrecic L, Zhou J, Jeong $\mathrm{H}$, Then F, Rosas HD, et al. Genome-wide expression profiling of human blood reveals biomarkers for Huntington's disease. Proc Natl Acad Sci U S A (2005) 102:11023-8. doi:10.1073/ pnas.0504921102

24. Harjes P, Wanker EE. The hunt for Huntingtin function: interaction partners tell many different stories. Trends Biochem Sci (2003) 28:425-33. doi:10.1016/ S0968-0004(03)00168-3

25. Li SH, Li XJ. Huntingtin-protein interactions and the pathogenesis of Huntington's disease. Trends Genet (2004) 20:146-54. doi:10. 1016/j.tig.2004.01.008

26. Suhr ST, Senut MC, Whitelegge JP, Faull KF, Cuizon DB, Gage FH. Identities of sequestered proteins in aggregates from cells with induced polyglutamine expression. J Cell Biol (2001) 153:283-94 doi:10.1083/jcb.153.2.283

27. Shimohata T, Nakajima T, Yamada M, Uchida C, Onodera O, Naruse S, et al. Expanded polyglutamine stretches interact with TAFII130, interfering with CREB-dependent transcription. Nat Genet (2000) 26:29-36. doi:10.1038/79139

28. Dunah AW, Jeong H, Griffin A, Kim YM, Standaert DG, Hersch SM, et al. Spl and TAFII130 transcriptional activity disrupted in early Huntington's disease. Science (2002) 296:2238-43. doi:10.1126/ science.1072613

29. Steffan JS, Kazantsev A, SpasicBoskovic O, Greenwald M, Zhu YZ, Gohler H, et al. The Huntington's disease protein interacts with p53 and CREB-binding protein and represses transcription. Proc Natl Acad Sci U S A (2000) 97:6763-8. doi:10.1073/pnas. 100110097

30. Nucifora FC Jr, Sasaki M, Peters MF, Huang H, Cooper JK, Yamada $\mathrm{M}$, et al. Interference by Huntingtin and atrophin-1 with cbpmediated transcription leading to cellular toxicity. Science (2001) 291:2423-8. doi:10.1126/science. 1056784 
31. Boutell JM, Thomas P, Neal JW, Weston VJ, Duce J, Harper PS, et al. Aberrant interactions of transcriptional repressor proteins with the Huntington's disease gene product, Huntingtin. Hum $\mathrm{Mol}$ Genet (1999) 8:1647-55. doi:10. 1093/hmg/8.9.1647

32. Grison A, Mantovani F, Comel A, Agostoni E, Gustincich S, Persichetti F, et al. Ser46 phosphorylation and prolyl-isomerase Pin1mediated isomerization of p53 are key events in p53-dependent apoptosis induced by mutant Huntingtin. Proc Natl Acad Sci U S A (2011) 108:17979-84. doi:10. 1073/pnas.1106198108

33. Bae BI, Xu H, Igarashi S, Fujimuro M, Agrawal N, Taya Y, et al. p53 mediates cellular dysfunction and behavioral abnormalities in Huntington's disease. Neuron (2005) 47:29-41. doi:10.1016/ j.neuron.2005.06.005

34. Lonze BE, Ginty DD. Function and regulation of CREB family transcription factors in the nervous system. Neuron (2002) 35:605-23. doi:10.1016/S08966273(02)00828-0

35. Lin J, Handschin C, Spiegelman BM. Metabolic control through the PGC-1 family of transcription coactivators. Cell Metab (2005) 1:361-70.

36. Squitieri F, Cannella M, Simonelli M. CAG mutation effect on rate of progression in Huntington's disease. Neurol Sci (2002) 23(Suppl 2):S107-8. doi:10.1007/ s100720200092

37. Almeida S, Sarmento-Ribeiro AB, Januario C, Rego AC, Oliveira CR. Evidence of apoptosis and mitochondrial abnormalities in peripheral blood cells of Huntington's disease patients. Biochem Biophys Res Commun (2008) 374: 599-603. doi:10.1016/j.bbrc.2008. 07.009

38. Orr AL, Li S, Wang CE, Li H, Wang J, Rong J, et al. N-terminal mutant Huntingtin associates with mitochondria and impairs mitochondrial trafficking. J Neurosci (2008) 28:2783-92. doi:10.1523/ JNEUROSCI.0106-08.2008

39. Cui L, Jeong H, Borovecki F, Parkhurst CN, Tanese N, Krainc D. Transcriptional repression of PGC-lalpha by mutant Huntingtin leads to mitochondrial dysfunction and neurodegeneration. Cell (2006) 127:59-69. doi:10. 1016/j.cell.2006.09.015

40. Xiang Z, Valenza M, Cui L, Leoni V, Jeong HK, Brilli E, et al.
Peroxisome-proliferator-activated receptor gamma coactivator 1 alpha contributes to dysmyelination in experimental models of Huntington's disease. J Neurosci (2011) 31: 9544-53. doi:10.1523/ JNEUROSCI.1291-11.2011

41. Hardingham GE, Bading $H$. The Yin and Yang of NMDA receptor signalling. Trends Neurosci (2003) 26:81-9. doi:10.1016/S01662236(02)00040-1

42. Roze E, Betuing S, Deyts C, Marcon E, Brami-Cherrier K, Pages C, et al. Mitogen- and stress-activated protein kinase-1 deficiency is involved in expanded-Huntingtininduced transcriptional dysregulation and striatal death. FASEB $J$ (2008) 22:1083-93. doi:10.1096/fj. 07-9814

43. Martin E, Betuing S, Pages C, Cambon K, Auregan G, Deglon N, et al. Mitogen- and stress-activated protein kinase 1-induced neuroprotection in Huntington's disease: role on chromatin remodeling at the PGC-1-alpha promoter. Hum Mol Genet (2011) 20:2422-34. doi: $10.1093 / \mathrm{hmg} / \mathrm{ddr} 148$

44. Shi T, Wang F, Stieren E, Tong Q. SIRT3, a mitochondrial sirtuin deacetylase, regulates mitochondrial function and thermogenesis in brown adipocytes. I Biol Chem (2005) 280:13560-7. doi:10.1074/ jbc.M414670200

45. Palacios OM, Carmona JJ, Michan S, Chen KY, Manabe Y, Ward JL 3rd, et al. Diet and exercise signals regulate SIRT3 and activate AMPK and PGC-1alpha in skeletal muscle. Aging (Albany NY). (2009) 1:771-83.

46. Fu J, Jin J, Cichewicz RH, Hageman SA, Ellis TK, Xiang L, et al. trans-(-)- $\epsilon$-Viniferin increases mitochondrial sirtuin 3 (SIRT3), activates AMP-activated protein kinase (AMPK), and protects cells in models of Huntington Disease. J Biol Chem (2012) 287:24460-72. doi:10.1074/jbc. M112.382226

47. Jeong H, Cohen DE, Cui L, Supinski A, Savas JN, Mazzulli JR, et al. Sirtl mediates neuroprotection from mutant Huntingtin by activation of the TORC1 and CREB transcriptional pathway. Nat Med (2011) 18(1):159-65. doi:10.1038/ nm.2559

48. Jiang M, Wang J, Fu J, Du L, Jeong $\mathrm{H}$, West $\mathrm{T}$, et al. Neuroprotective role of Sirt1 in mammalian models of Huntington's disease through activation of multiple Sirtl targets.
Nat Med (2011) 18:153-8. doi:10. 1038/nm. 2558

49. Zuccato C, Ciammola A, Rigamonti D, Leavitt BR, Goffredo $\mathrm{D}$, Conti L, et al. Loss of Huntingtin-mediated BDNF gene transcription in Huntington's disease. Science (2001) 293:493-8. doi:10.1126/science.1059581

50. Gauthier LR, Charrin BC, BorrellPagès $M$, Dompierre JP, Rangone $\mathrm{H}$, Cordelières $\mathrm{FP}$, et al. Huntingtin controls neurotrophic support and survival of neurons by enhancing BDNF vesicular transport along microtubules. Cell (2004) 118:127-38. doi:10.1016/j. cell.2004.06.018

51. Zuccato C, Tartari M, Crotti A, Goffredo D, Valenza M, Conti L, et al. Huntingtin interacts with REST/NRSF to modulate the transcription of NRSE-controlled neuronal genes. Nat Genet (2003) 35:76-83. doi:10.1038/ng1219

52. Zuccato C, Belyaev N, Conforti P, Ooi L, Tartari M, Papadimou E, et al. Widespread disruption of repressor element-1 silencing transcription factor/neuronrestrictive silencer factor occupancy at its target genes in Huntington's disease. J Neurosci (2007) 27:6972-83. doi:10.1523/ JNEUROSCI.4278-06.2007

53. Ferrer J, Goutan E, Marin C, Rey MJ, Ribalta T. Brain-derived neurotrophic factor in Huntington's disease. Brain Res (2000) 866:25761.

54. Strand AD, Baquet ZC, Aragaki AK, Holmans P, Yang L, Cleren C, et al. Expression profiling of Huntington's disease models suggests that brain-derived neurotrophic factor depletion plays a major role in striatal degeneration. J Neurosci (2007) 27:11758-68. doi:10.1523/ JNEUROSCI.2461-07.2007

55. Xie Y, Hayden MR, Xu B. BDNF overexpression in the forebrain rescues Huntington's disease phenotypes in YAC128 mice. J Neurosci (2010) 30:14708-18. doi:10.1523/ JNEUROSCI.1637-10.2010

56. Canals JM, Pineda JR, TorresPeraza JF, Bosch M, Martin-Ibanez R, Munoz MT, et al. Brain-derived neurotrophic factor regulates the onset and severity of motor dysfunction associated with enkephalinergic neuronal degeneration in Huntington's disease. J Neurosci (2004) 24:7727-39. doi:10.1523/ JNEUROSCI.1197-04.2004

57. Gharami K, Xie Y, An JJ, Tonegawa $\mathrm{S}, \mathrm{Xu}$ B. Brain-derived neurotrophic factor over-expression in the forebrain ameliorates Huntington's disease phenotypes in mice. J Neurochem (2008) 105:369-79. doi:10.1111/j.14714159.2007.05137.x

58. Johnson R, Zuccato C, Belyaev ND, Guest DJ, Cattaneo E, Buckley NJ. A microRNA-based gene dysregulation pathway in Huntington's disease. Neurobiol Dis (2008) 29:438-45. doi:10.1016/j. nbd.2007.11.001

59. Conforti P, Mas Monteys A, Zuccato C, Buckley NJ, Davidson B, Cattaneo E. In vivo delivery of DN:REST improves transcriptional changes of REST-regulated genes in HD mice. Gene Ther (2013) 20:678-85. doi:10.1038/gt. 2012.84

60. Bannister AJ, Kouzarides T. Regulation of chromatin by histone modifications. Cell Res (2011) 21:381-95. doi:10.1038/cr.2011.22

61. Li B, Carey M, Workman JL. The role of chromatin during transcription. Cell (2007) 128:707-19. doi:10.1016/j.cell.2007.01.015

62. Marks PA, Richon VM, Breslow R, Rifkind RA. Histone deacetylase inhibitors as new cancer drugs. Curr Opin Oncol (2001) 13:477-83. doi:10.1097/ 00001622-200111000-00010

63. Kazantsev A, Preisinger E, Dranovsky A, Goldgaber D, Housman D. Insoluble detergent-resistant aggregates form between pathological and nonpathological lengths of polyglutamine in mammalian cells. Proc Natl Acad Sci U S A (1999) 96:11404-9. doi:10.1073/pnas.96.20.11404

64. Steffan JS, Bodai L, Pallos J, Poelman M, McCampbell A, Apostol BL, et al. Histone deacetylase inhibitors arrest polyglutamine-dependent neurodegeneration in Drosophila. Nature (2001) 413:739-43. doi:10.1038/35099568

65. Ferrante RJ, Kubilus JK, Lee J, Ryu H, Beesen A, Zucker B, et al. Histone deacetylase inhibition by sodium butyrate chemotherapy ameliorates the neurodegenerative phenotype in Huntington's disease mice. J Neurosci (2003) 23:9418-27.

66. Hockly E, Richon VM, Woodman B, Smith DL, Zhou X, Rosa E, et al. Suberoylanilide hydroxamic acid, a histone deacetylase inhibitor, ameliorates motor deficits in a mouse model of Huntington's disease. Proc Natl Acad Sci U S A (2003) 100:2041-6. doi:10.1073/ pnas. 0437870100 
67. Gardian G, Browne SE, Choi DK, Klivenyi P, Gregorio J, Kubilus JK, et al. Neuroprotective effects of phenylbutyrate in the N17182Q transgenic mouse model of Huntington's disease. J Biol Chem (2005) 280:556-63.

68. Sadri-Vakili G, Bouzou B, Benn CL, Kim MO, Chawla P, Overland $\mathrm{RP}$, et al. Histones associated with downregulated genes are hypoacetylated in Huntington's disease models. Hum Mol Genet (2007) 16:1293-306. doi:10.1093/ hmg/ddm078

69. Codd R, Braich N, Liu J, Soe CZ, Pakchung AA. Zn(II)-dependent histone deacetylase inhibitors: suberoylanilide hydroxamic acid and trichostatin A. Int J Biochem Cell Biol (2009) 41:736-9. doi:10.1016/j.biocel.2008.05.026

70. Bobrowska A, Paganetti P, Matthias P, Bates GP. Hdac6 knock-out increases tubulin acetylation but does not modify disease progression in the R6/2 mouse model of Huntington's disease. PLoS ONE (2011) 6:e20696. doi:10. 1371/journal.pone.0020696

71. Moumné L, Campbell K, Howland D, Ouyang Y, Bates GP. Genetic knock-down of HDAC3 does not modify disease-related phenotypes in a mouse model of Huntington's disease. PLoS ONE (2012) 7:e31080. doi:10. 1371/journal.pone.0031080

72. Benn CL, Butler R, Mariner L, Nixon J, Moffitt $\mathrm{H}$, Mielcarek $\mathrm{M}$, et al. Genetic knock-down of HDAC7 does not ameliorate disease pathogenesis in the R6/2 mouse model of Huntington's disease. PLoS ONE (2009) 4: e5747. doi:10.1371/journal.pone. 0005747

73. Munoz-Sanjuan I, Bates GP. The importance of integrating basic and clinical research toward the development of new therapies for Huntington disease. J Clin Invest (2011) 121:476-83. doi:10.1172/ JCI45364

74. Ryu H, Lee J, Hagerty SW, Soh BY, McAlpin SE, Cormier KA, et al. ESET/SETDB1 gene expression and histone H3 (K9) trimethylation in Huntington's disease. Proc Natl Acad Sci U S A (2006) 103:19176-81. doi:10.1073/pnas. 0606373103

75. Yang L, Mei Q, ZielinskaKwiatkowska A, Matsui Y, Blackburn ML, Benedetti D, et al. An ERG (ets-related gene)associated histone methyltransferase interacts with histone deacetylases $1 / 2$ and transcription co-repressors $\mathrm{mSin} 3 \mathrm{~A} / \mathrm{B}$. Biochem J (2003) 369:651-7. doi:10.1042/BJ20020854

76. Stack EC, Dedeoglu A, Smith KM, Cormier K, Kubilus JK, Bogdanov $M$, et al. Neuroprotective effects of synaptic modulation in Huntington's disease R6/2 mice. J Neurosci (2007) 27:12908-15. doi:10.1523/ JNEUROSCI.4318-07.2007

77. Kim MO, Chawla P, Overland RP, Xia E, Sadri-Vakili G, Cha JH. Altered histone monoubiquitylation mediated by mutant Huntingtin induces transcriptional dysregulation. J Neurosci (2008) 28:3947-57. doi:10.1523/JNEUROSCI.566707.2008

78. Ballestar E, Abad C, Franco L. Core histones are glutaminyl substrates for tissue transglutaminase. J Biol Chem (1996) 271:18817-24. doi: 10.1074/jbc.271.31.18817

79. Ballestar E, Franco L. Use of the transglutaminase reaction to study the dissociation of histone $\mathrm{N}$-terminal tails from DNA in nucleosome core particles. Biochemistry (1997) 36:5963-9. doi: 10.1021/bi9626620

80. Ballestar E, Wolffe AP. MethylCpG-binding proteins. Targeting specific gene repression. Eur $J$ Biochem (2001) 268:1-6. doi:10. 1046/j.1432-1327.2001.01869.x

81. Karpuj MV, Garren H, Slunt H, Price DL, Gusella J, Becher MW, et al. Transglutaminase aggregates Huntingtin into nonamyloidogenic polymers, and its enzymatic activity increases in Huntington's disease brain nuclei. Proc Natl Acad Sci U S A (1999) 96:7388-93. doi:10.1073/pnas.96. 13.7388

82. Karpuj MV, Becher MW, Springer JE, Chabas D, Youssef S, Pedotti $\mathrm{R}$, et al. Prolonged survival and decreased abnormal movements in transgenic model of Huntington disease, with administration of the transglutaminase inhibitor cystamine. Nat Med (2002) 8:143-9. doi:10.1038/nm0202-143

83. McConoughey SJ, Basso M, Niatsetskaya ZV, Sleiman SF, Smirnova NA, Langley BC, et al. Inhibition of transglutaminase 2 mitigates transcriptional dysregulation in models of Huntington disease. EMBO Mol Med (2010) 2:349-70. doi:10. 1002/emmm.201000084

84. Ng CW, Yildirim F, Yap YS, Dalin S, Matthews BJ, Velez PJ, et al. Extensive changes in DNA methylation are associated with expression of mutant Huntingtin. Proc Natl Acad Sci U S A (2013) 110:2354-9. doi: $10.1073 /$ pnas. 1221292110

85. Kim VN, Han J, Siomi MC. Biogenesis of small RNAs in animals. Nat Rev Mol Cell Biol (2009) 10:126-39. doi:10.1038/nrm2632

86. Lee Y, Ahn C, Han J, Choi H, Kim J, Yim J, et al. The nuclear RNase III Drosha initiates microRNA processing. Nature (2003) 425:415-9. doi:10.1038/nature01957

87. Denli AM, Tops BB, Plasterk RH, Ketting RF, Hannon GJ. Processing of primary microRNAs by the Microprocessor complex. Nature (2004) 432:231-5. doi:10. 1038/nature03049

88. Yi R, Qin Y, Macara IG, Cullen BR. Exportin-5 mediates the nuclear export of pre-microRNAs and short hairpin RNAs. Genes Dev (2003) 17:3011-6. doi:10.1101/ gad.1158803

89. Lund E, Guttinger S, Calado A, Dahlberg JE, Kutay U. Nuclear export of microRNA precursors. Science (2004) 303:95-8. doi:10. 1126/science.1090599

90. Hutvagner G, McLachlan J, Pasquinelli AE, Balint E, Tuschl T, Zamore PD. A cellular function for the RNA-interference enzyme Dicer in the maturation of the let-7 small temporal RNA. Science (2001) 293:834-8. doi:10.1126/science.1062961

91. Salzman DW, Shubert-Coleman J, Furneaux H. P68 RNA helicase unwinds the human let-7 microRNA precursor duplex and is required for let-7-directed silencing of gene expression. J Biol Chem (2007) 282:32773-9. doi:10.1074/ jbc.M705054200

92. Guo H, Ingolia NT, Weissman JS, Bartel DP. Mammalian microRNAs predominantly act to decrease target mRNA levels. Nature (2010) 466:835-40. doi:10.1038/nature09267

93. Humphreys DT, Westman BJ, Martin DI, Preiss T. MicroRNAs control translation initiation by inhibiting eukaryotic initiation factor 4E/cap and poly(A) tail function. Proc Natl Acad Sci U S A (2005) 102:16961-6. doi:10.1073/ pnas.0506482102

94. Pillai RS, Bhattacharyya SN, Artus CG, Zoller T, Cougot N, Basyuk $\mathrm{E}$, et al. Inhibition of translational initiation by Let-7 MicroRNA in human cells. Science (2005) 309:1573-6. doi:10.1126/science. 1115079

95. Wu L, Fan J, Belasco JG. MicroRNAs direct rapid deadenylation of
mRNA. Proc Natl Acad Sci U S A (2006) 103:4034-9. doi:10.1073/ pnas.0510928103

96. Lim LP, Lau NC, Garrett-Engele P, Grimson A, Schelter JM, Castle J, et al. Microarray analysis shows that some microRNAs downregulate large numbers of target mRNAs. Nature (2005) 433:769-73. doi:10.1038/ nature03315

97. Kosik KS. The neuronal microRNA system. Nat Rev Neurosci (2006) 7:911-20. doi:10.1038/nrn2037

98. Schaefer A, O'Carroll D, Tan CL, Hillman D, Sugimori $M$, Llinas $\mathrm{R}$, et al. Cerebellar neurodegeneration in the absence of microRNAs. J Exp Med (2007) 204:1553-8. doi:10.1084/jem. 20070823

99. Cuellar TL, Davis TH, Nelson PT, Loeb GB, Harfe BD, Ullian E, et al. Dicer loss in striatal neurons produces behavioral and neuroanatomical phenotypes in the absence of neurodegeneration. Proc Natl Acad Sci U S A (2008) 105:5614-9. doi:10.1073/ pnas.0801689105

100. Lee ST, Chu K, Im WS, Yoon HJ, Im JY, Park JE, et al. Altered microRNA regulation in Huntington's disease models. Exp Neurol (2011) 227:172-9. doi:10.1016/j. expneurol.2010.10.012

101. Soldati C, Bithell A, Johnston C, Wong KY, Stanton LW, Buckley NJ. Dysregulation of RESTregulated coding and non-coding RNAs in a cellular model of Huntington's disease. J Neurochem (2013) 124:418-30. doi:10.1111/ jnc. 12090

102. Packer AN, Xing Y, Harper SQ, Jones L, Davidson BL. The bifunctional microRNA miR9/miR-9* regulates REST and CoREST and is downregulated in Huntington's disease. J Neurosci (2008) 28:14341-6. doi:10.1523/ JNEUROSCI.2390-08.2008

103. Savas JN, Makusky A, Ottosen S, Baillat D, Then F, Krainc D, et al. Huntington's disease protein contributes to RNA-mediated gene silencing through association with Argonaute and $\mathrm{P}$ bodies. Proc Natl Acad Sci U S A (2008) 105:10820-5. doi:10.1073/ pnas.0800658105

104. Banez-Coronel M, Porta S, Kagerbauer B, Mateu-Huertas E, Pantano L, Ferrer I, et al. A pathogenic mechanism in Huntington's disease involves small CAG-repeated RNAs with neurotoxic activity. PLoS Genet (2012) 8: 
e1002481. doi:10.1371/journal. pgen.1002481

105. Martí E, Pantano L, Bañez-Coronel M, Llorens F, Miñones-Moyano E, Porta S, et al. A myriad of miRNA variants in control and Huntington's disease brain regions detected by massively parallel sequencing. Nucleic Acids Res (2010) 38:7219-35. doi:10.1093/ nar/gkq575

106. Jovicic A, Zaldivar Jolissaint JF, Moser R, Silva Santos MF, Luthi-Carter R. MicroRNA22 (miR-22) overexpression is neuroprotective via general anti-apoptotic effects and may also target specific Huntington's disease-related mechanisms. PLoS ONE (2013) 8:e54222. doi:10. 1371/journal.pone.0054222

107. Cheng PH, Li CL, Chang YF, Tsai SJ, Lai YY, Chan AW, et al. miR-196a ameliorates phenotypes of Huntington disease in cell, transgenic mouse, and induced pluripotent stem cell models. Am J Hum Genet (2013) 93: 306-12. doi:10.1016/j.ajhg.2013. 05.025
Conflict of Interest Statement: The authors declare that the research was conducted in the absence of any commercial or financial relationships that could be construed as a potential conflict of interest.

Received: 30 April 2013; accepted: 20 August 2013; published online: 23 October 2013.

Citation: Moumné L, Betuing $S$ and Caboche J (2013) Multiple aspects of gene dysregulation in Huntington's disease. Front. Neurol. 4:127. doi: 10.3389/fneur.2013.00127
This article was submitted to Neurodegeneration, a section of the journal Frontiers in Neurology.

Copyright $\odot 2013$ Moumné, Betuing and Caboche. This is an open-access article distributed under the terms of the Creative Commons Attribution License (CC $B Y)$. The use, distribution or reproduction in other forums is permitted, provided the original author(s) or licensor are credited and that the original publication in this journal is cited, in accordance with accepted academic practice. No use, distribution or reproduction is permitted which does not comply with these terms. 